\title{
Migraine, headache, and survival in women
}

\author{
W E WATERS, M J CAMPBELL, P C ELWOOD
}

\begin{abstract}
A population study of 1310 women aged 45-64 years determined the prevalence of headache and migraine in the preceding year. To investigate the hypothesis that women with migraine had a higher mortality rate, these women were followed up nearly 12 years later. Unexpectedly, the mortality was found to be higher in women without headaches. Women with headaches and migraine had a relative risk of dying of $0.72(95 \%$ confidence interval $0.52-1.00)$ compared with those without headaches.
\end{abstract}

\section{Introduction}

There is little information from epidemiological studies on the association of migraine or other headaches with mortality. Serious intracranial disease such as brain tumours and aneurysms are associated with headache but are uncommon in the general population. Attacks of migraine have been associated with neurological disturbances ${ }^{1}$ which may rarely cause death. ${ }^{23}$ Headaches accompany and precede cerebrovascular disease ${ }^{4} 5$ and also precede myocardial infarction. ${ }^{6}$ In a study of women below 70 years with migraine Graham $^{7}$ found risk ratios of 1.6 for high blood pressure, 6.6 for heart attack, and 1.9 for death but it is not clear how these data were obtained. If headache were associated with hypertension associations with morbidity and mortality would be expected. Epidemiological evidence, however, suggests only a very weak association, and probably hypertension accounts for only a small percentage of headache in the community. ${ }^{8}$ Sufferers from severe headache sometimes worry that they may have an increased risk of developing a stroke, perhaps partly from the severity and distribution of the headache and partly from a family history of strokes, which may of course be coincidental.

We report on the prevalence of headache in nearly 3000 women in a community study conducted in $1967^{\circ}$ and the mortality observed over a follow up period of nearly 12 years.

\section{Subjects and methods}

In 1967 all women aged between 20 and 64 years living in a defined area of the Rhondda valley in south Wales were invited to attend a

\footnotetext{
University Department of Community Medicine and Medical Statistics, Southampton General Hospital, Southampton SO9 4XY W E WATERS, MB, FFCM, professor of community medicine M J CAMPBELL, MSC, PHD, lecturer in medical statistics

Medical Research Council Epidemiology Unit, Cardiff CF2 3AS P C ELWOOD, MD, FFCM, director

Correspondence to: Professor W E Waters.
}

survey. Over $86 \%$ cooperated. The survey was mainly haematological, but questions were also asked about several aspects of health, including questions about headache in the year before the survey. To identify three features of migraine those with headaches were asked: (1) Are your headaches sometimes on one side only? (2) Before you get a headache do you know that one is coming ? (3) When you get a headache do you feel sick or vomit? Detailed clinical validation of the questionnaire in this same population found that $21 \%$ of those with only one of the three migrainous features were diagnosed by a neurologist as migraine, whereas $45 \%$ of those with two features and $88 \%$ of those with all three features were so diagnosed. ${ }^{9}$

In 1979 these same women were followed up by home visiting to ascertain mortality. Survival was assumed if the subject or a close relative was interviewed or if a letter was received from the subject. For every death before the end of 1978 a certified copy of the death certificate was inspected. Causes of death were coded according to the International Classification of Diseases (ICD; 8 th revision). Statistical analysis was carried out using the computer package GENSTAT, ${ }^{10}$ as described.11 In particular, multiple logistic regression was used to assess the effect of various factors on the probability of dying in the follow up period.

\section{Results}

A total of 2932 women were followed up. Table I shows their age distribution and the proportions who at the time of the 1967 survey gave a history of headache and reported two or three features of migraine. The proportion of women who had had headache increased slightly with age to a maximum at 35-44 years and then declined.

TABLE I-Women in survey with history of headache and reporting two or three features* of migraine in the preceding year distributed by age in 1967

\begin{tabular}{lllllll}
\hline & \multicolumn{6}{c}{ Age in years } \\
\cline { 2 - 7 } & $20-$ & $25-$ & $35-$ & $45-$ & $\geqslant 55$ & Total \\
\hline $\begin{array}{l}\text { No seen in } \\
\text { survey }\end{array}$ & 293 & 675 & 650 & 736 & 578 & 2932 \\
$\begin{array}{c}\text { No of completed } \\
\text { question- } \\
\text { naires }\end{array}$ & 277 & 636 & 640 & 732 & 578 & 2863 \\
$\begin{array}{c}\text { No(\%) with } \\
\text { headache }\end{array}$ & $231(83)$ & $536(84)$ & $560(88)$ & $545(74)$ & $398(69)$ & $2270(79)$ \\
$\begin{array}{c}\text { No(\%) with } \\
\text { two or three } \\
\text { migrainous } \\
\text { features* }\end{array}$ & $57(21)$ & $182(29)$ & $168(26)$ & $178(24)$ & $101(17)$ & $686(24)$ \\
\hline
\end{tabular}

- Features were: unilateral distribution, warning, nausea.

In the follow up data there were a few small discrepancies in the sample in those aged 20-34 years and minor discrepancies of age in those above 35 , which may have been due to the inconsistent use of either recorded age or age calculated from the date of birth. Nevertheless, of the 1504 women above 35 years who had had headaches when seen in 1967,1503 were followed up to the end of 1978 . Women under the age of 45 were excluded from the original analyses because only a small proportion ( $3 \%$ ) had died during follow up. A total of 185 deaths occurred among the women who had been aged 45-64 years in 1967. Table II shows the causes of death among these women distributed 
TABLE II-Mortality and causes of death during follow up period among women aged 45-64 years when first seen in 1967 who had given and not given a history of headache. Figures are numbers (\%) of women

\begin{tabular}{|c|c|c|c|c|c|}
\hline & \multirow{2}{*}{$\begin{array}{l}\text { No headache } \\
\text { (1967) }\end{array}$} & \multicolumn{3}{|c|}{$\begin{array}{l}\text { Headache and No of } \\
\text { migrainous features (1967) }\end{array}$} & \multirow[b]{2}{*}{ Total } \\
\hline & & 0 & 1 & 2 and 3 & \\
\hline \multirow{3}{*}{$\begin{array}{l}\text { Cancer } \\
\text { Ischaemic heart } \\
\text { disease (ICD } \\
4 \cdot 10-4 \cdot 14) \\
\text { Cerebrovascular } \\
\text { accident (ICD } \\
430-438 \text { ) } \\
\text { Other } \\
\text { Alive }\end{array}$} & $14(3 \cdot 8)$ & $16(4 \cdot 7)$ & $11(3.4)$ & $8(2.9)$ & 49 \\
\hline & $20(5 \cdot 4)$ & $7(2 \cdot 1)$ & $10(3 \cdot 1)$ & $10(3 \cdot 6)$ & 47 \\
\hline & $\begin{array}{r}12(3.3) \\
20(5 \cdot 4) \\
301(82 \cdot 0)\end{array}$ & $\begin{array}{r}6(1 \cdot 8) \\
17(5 \cdot 0) \\
292(86.4)\end{array}$ & $\begin{array}{r}5(1 \cdot 5) \\
9(2 \cdot 8) \\
291(89 \cdot 3)\end{array}$ & $\begin{array}{c}6(2 \cdot 2) \\
14(5 \cdot 0) \\
241(86 \cdot 4)\end{array}$ & $\begin{array}{r}29 \\
60 \\
1125\end{array}$ \\
\hline Total & $367(100 \cdot 0)$ & $338(100 \cdot 0)$ & $326(100 \cdot 0)$ & $279(100 \cdot 0)$ & 1310 \\
\hline
\end{tabular}

according to whether or not they had given a history of headache when seen in 1967.

The crude death rate of the total cohort during the follow up period was $12 \cdot 1$ deaths $/ 1000$ a year. The overall standardised mortality ratio compared with the national figures for England and Wales during 1967-78 was 106. This is slightly lower than would be expected for social classes III-V, which would describe most of the women. Our cohort, however, was probably slightly healthier than the national average because, though an attempt was made to see all subjects within the defined area, chronic invalids and people who were housebound or in hospital were less likely to have cooperated in the original survey.

Table III shows the risk of dying during the follow up period as calculated by multiple logistic regression to allow for age. The risk of death was less among those who had had headache in 1967 compared with those who had not had headache. The risk was also less among those who had had at least one migrainous feature compared with those who had had headache without any of the three migrainous features and those who had not had headaches at all. Analysis of the 29 deaths among women aged 35-44 at the time of the original survey showed that the death rate in the no headache group (seven deaths) was more than twice that in the headache and migraine groups, but the numbers were small.

TABLE III-Relative risk of dying (allowing for age*) in follow up period

\begin{tabular}{lcc}
\hline & Risk & $\begin{array}{c}95 \% \text { Confidence } \\
\text { interval }\end{array}$ \\
\hline $\begin{array}{l}\text { All headaches (compared with no headaches) } \\
\begin{array}{c}\text { Headache with one or more migrainous features } \\
\text { (compared with headaches only and no headaches) }\end{array}\end{array}$ & 0.72 & $0.52-1.00$ \\
\hline
\end{tabular}

* Allowing for age, smoking, and analgesic taking results were: all headaches risk 0.71 $(95 \%$ confidence interval $0.50-0 \cdot 99) ;$ headach
risk $0.76(95 \%$ confidence interval $0 \cdot 54-1 \cdot 05)$.

\section{Discussion}

Migraine can be a debilitating disease, and in view of the few published comments on mortality ${ }^{2-7}$ this analysis was undertaken to determine whether or not sufferers from migraine and other headaches have a higher than expected mortality.

A surprising finding (table II) was that the proportion of our cohort who were still alive in 1979 in the no headache group $(82 \%)$ was lower than the proportion in any other group. The excess deaths in the no headache group were apparently mainly due to ischaemic heart disease and cerebrovascular accidents, two conditions previously believed to be associated with head- ache. Multiple logistic regression analysis showed that the relative risk of death was less in those with headache and probably less in those with migraine compared with other women of the same age.

These results were completely unexpected. We can state quite definitely that the women aged 45-64 years who had had headache and migraine in 1967 did not subsequently have an increased risk of dying.

There are two possible explanations. Firstly, although epidemiological studies show that the prevalence of headache does not increase with blood pressure, the reporting of headache may lead to measurement of the blood pressure. Thus patients with headache may be more likely to have hypertension diagnosed and treated. This might explain the reduction in mortality in women with headache. Secondly, the results of this follow up were based on a period prevalence of headache in the year before the survey and we do not know the lifetime history of headache of these women. The prevalence of headache and migraine declines with age, so that their presence is sometimes thought to indicate that the arteries are still youthful. Their disappearance may indicate that the arteries are aging and "hardening." Hence women with headaches and migraine and advancing arterial disease possibly lose their headaches earlier than those with less arterial disease, and these women would be expected to have a high mortality from cardiovascular disease. Thus it is possible that the higher mortality of the women who were without headache at the time of the original survey was due to the presence of ex-sufferers of headache and migraine in the no headache group. The survey did not determine those who had suffered migraine in the past, so that we cannot say whether women who had experienced migraine at any time in their lives had a lower mortality rate.

While either of these possibilities could explain our findings, we have no direct evidence, either way, from the present study. It is probably the first large scale follow up survey of headache in a population sample of women, and further studies are clearly desirable. The results of our study, despite the possible explanations, should give considerable reassurance to women with headache and migraine and to their clinical advisors.

\section{References}

1 Lance JW. Mechanism and management of headache. 4th ed. London: Butterworths, 1978

2 Guest IA, Woolf AL. Fatal infarction of brain in migraine. Br Med 71964 i :225-6.

3 Neligan P. Respiratory arrest in familial hemiplegic migraine. Br Med $\mathfrak{f}$ 1977; ii :732-4.

4 Edmeads J. The headaches of ischemic cerebrovascular disease. Headache $1979 ; 19: 345-9$.

5 Spaccavento LJ, Solomon GD, Mani S. An association between strokes and migraines in young adults. Headache $1981 ; 21: 121$.

- Klatsky AL, Fridman GD, Siegelaub AB. Medical history questions predictive of myocardial infarction. F Chronic Dis 1976;29:683-96.

7 Graham JR. Headache related to a variety of medical disorders. In: Appenzeller $\mathrm{O}$, ed. Pathogenesis and treatment of headache. New York: Spectrum, 1976:49-67.

8 Anonymous. Headache and blood-pressure. Lancet 1976;i:896-7.

- Waters WE, O'Connor PJ. Epidemiology of headache and migraine in women. F Neurol Neurosurg Psychiatry 1971 ;34:148-53.

10 Alvey NG, Banfield CF, Baxter RI, et al. GENST AT: a general statistical program. Harpenden: Statistics Department, Rothamsted Experimental Station, 1980

11 Campbell MJ. The use of GENSTAT in analysing a large follow-up survey. Statistics in Medicine $1983 ; 2: 223-8$.

(Accepted 11 August 1983) 